\title{
Forecasting Analysis of Covid-19 Cases with Wavelet Neural Network and Time Series Approach
}

\author{
Asli Kaya \\ Department of Institutional Planning and Development \\ Eskisehir Technical University \\ Eskisehir \\ Turkey
}

\author{
Fatih Cemrek \\ Department of Statistics \\ Eskisehir Osmangazi University \\ Eskisehir \\ Turkey
}

\author{
Ozer Ozdemir \\ Department of Statistics \\ Eskisehir Technical University \\ Eskisehir \\ Turkey
}

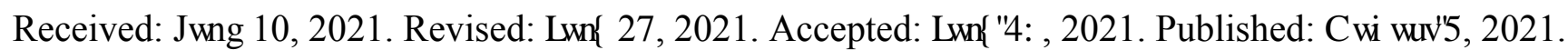

\begin{abstract}
COVID-19 is a respiratory disease caused by a novel coronavirus first detected in December 2019. As the number of new cases increases rapidly, pandemic fatigue and public disinterest in different response strategies are creating new challenges for government officials in tackling the pandemic. Therefore, government officials need to fully understand the future dynamics of COVID-19 to develop strategic preparedness and flexible response planning. In the light of the above-mentioned conditions, in this study, autoregressive integrated moving average (ARIMA) time series model and Wavelet Neural Networks (WNN) methods are used to predict the number of new cases and new deaths to draw possible future epidemic scenarios. These two methods were applied to publicly available data of the COVID-19 pandemic for Turkey, Italy, and the United Kingdom. In our analysis, excluding Turkey data, the WNN algorithm outperformed the ARIMA model in terms of forecasting consistency. Our work highlighted the promising validation of using wavelet neural networks when making predictions with very few features and a smaller amount of historical data.
\end{abstract}

Key-Words: - Time series analysis, Machine learning, Neural network, Wavelet, COVID-19

\section{INTRODUCTION}

With the development of computer technologies, human beings have been able to perform almost all their operations on innovative technologies. In addition, it is possible to find new methods. Therefore, the idea that the machine can think like a human was put forward in the 1980s. By the 1990s, Artificial Neural Networks technology has become widespread and has become a major development has been observed. One of the most attractive features of artificial neural networks is that they provide the opportunity to adapt the modeled system according to the changing behavior characteristics. Over the past decade, many researchers have been explored to improve ANN performance by optimizing methods, learning parameters or network structure by using various methods [1].

Looking at the literature, Jordan presents a representative logistic function that suggests posterior probability is a natural form of binary classification problem [2]. Liu and Yao developed the structure with two different types of activation 
functions, sigmoid and Gaussian functions by using Generalized Neural Networks (GNN) [3]. Sopena et al. presented several experiments showing (compared to ANNs) (commonly used criterion problems) two orders of magnitude of multilayer feedforward networks with sine activation functions learn faster and generalization capacity increases (with logistics activation function) [4]. Dorffner uses MLP and RBF networks to take advantage of both networks simultaneously [5]. Bodyanskiy presented its architecture and proposed learning algorithms. The proposed architecture is the wavelet neuron allowed the development of approach properties [6].

The ARIMA (p, d, q) model, which is used to reveal the properties of time series and also to predict the future, calculates the present value of the studied variable, as a weighted sum of past values and a combination of random shocks. The approach used to predict ARIMA models is called the "BoxJenkins approach". Box-Jenkins approach, technically called ARIMA forecasting model, aims to analyze the probability properties of economic time series. In ARIMA models, $Y_{t}$ can be explained with lagged values of $Y_{t}$ and probabilistic error terms [7], [8], [9].

\section{METHODS}

In this section, ARIMA and Wavelet Neural Network methods, which will be used in the analysis phase, will be expressed.

\section{A. Wavelet Neural Network}

Wavelet neural networks combine the theory of wavelets and neural networks into one. The wavelet, first proposed by Grossman and Morlet in the 1980s [10], is a mathematical theory and method of analysis that constitutes the deficiencies of the Fourier transform. Wavelet is a special waveform with an average of 0 and limited length. The wavelet function is generated through a series of basic transformations with a main wavelet function.

Wavelet neural network (WNN) or wavelet network $(\mathrm{WN})$ is a combination of two methods.

First, wavelet and neural network operations are performed separately. Input signal first hidden. It is decomposed by neurons in the layer using some wavelet basis. Ripple coefficients of which are then changed according to some learning algorithms or more summers. The second type combines the two theories. In this case, together with the summer weights of the wavelets, its translation and expansion are modified according to some learning algorithms.

This is to replace the sigmoid function used by neural networks with wavelets. In fact, the wavelet presents the transfer function for each neuron. The output function of wavelet nets [11] can be defined as follows:

$y(x)=\sum_{i=1}^{N}\left(W_{k} \varphi_{k}\left(\frac{x-b_{k}}{\alpha_{k}}\right)\right)$

$\mathrm{W}_{\mathrm{k}}$ are output weights, $\varphi_{\mathrm{k}}$ is a wavelet function, $b_{\mathrm{k}}$ are translation parameters and $\alpha_{\mathrm{k}}$ are expansion parameters.

In addition, wavelet networks are used in various application areas. For example, face recognition field [12]. Wavelet networks learn a series of images of several people's faces. After that, the system can classify a new image and recognize the person from an image of their face. In addition, wavelet networks can be used to recognize emotions [13]. It is a very interesting area of research. It aims to recognize facial emotions (fear, joy, sadness, surprise, disgust...). In addition, wavelet networks have been used to recognize hand gesture [14] and speech [15].

\section{B. ARIMA Models}

In order to apply ARIMA models, the mean and variance of the studied time series must be stationary. For a series to be stationary, its mean, variance, and autocovariance must be independent of the time variable. Otherwise, the series is not stationary and has a random course. The series do not tend to return to their mean values in the long run. Therefore, to make these series stationary, the difference of " $\mathrm{d}$ " from the previous values is taken. If a non-stationary $\mathrm{Y}_{\mathrm{t}}$ series becomes stationary after taking the difference $\mathrm{d}$ times, the new series is defined as $\mathrm{w}_{\mathrm{t}}$;

$\mathrm{w}_{\mathrm{t}}=\Delta^{\mathrm{d}} \mathrm{y}_{\mathrm{t}}=(1-\mathrm{L})^{\mathrm{d}} \mathrm{y}_{\mathrm{t}}$

$\mathrm{W}_{\mathrm{t}}$ represents the stationary series and the process is expressed as ARMA $(p, q)$. In this case, the model is;

$$
\begin{aligned}
& w_{t}=\phi_{1} w_{t-1}+\phi_{2} w_{t-2}+\ldots . .+\phi_{p} w_{t-p} \\
& +a_{t}-\theta_{1} a_{t-1}-\theta_{2} a_{t-2}-\ldots-\theta_{q} a_{t-q}
\end{aligned}
$$

If the difference series wt has an ARMA $(p, q)$ model, $Y_{t}$ is said to be an ARIMA $(p, d, q)$ model. 
Basic representation of the ARIMA (p,d,q) model in terms of original data, with the assumption $\delta \neq 0$; [16], [17]

$$
\begin{aligned}
& \Delta^{d} y_{t}=\delta+\gamma_{1} \Delta^{d} y_{t-1}+\gamma_{2} \Delta^{d} y_{t-2}+ \\
& \ldots .+\gamma_{p} \Delta^{d} y_{t-p}+a_{t}-\theta_{1} a_{t-1}-\ldots-\theta_{q} a_{t-q}
\end{aligned}
$$

Here, $p$ represents the number of AR (autoregressive) terms, $d$ the number of times the difference must be taken to bring the series to a stationary state, and q the number of MA (moving average) terms. After making the series stationary by taking the difference of $d$ of the examined series, the $p$ and $q$ values of the AR and MA processes should be determined for the ARIMA (p,d,q) model. The most important step for ARIMA models is to find these values.

Box-Jenkins, steps for selecting the ARIMA model: Specification; Determination of $\mathrm{p}, \mathrm{d}, \mathrm{q}$ degrees of ARIMA model. The autocorrelation function and partial autocorrelation function are used to determine the $\mathrm{p}$ and $\mathrm{q}$ values, and the results of the correlogram are also evaluated. Correlogram results; The aim of this study is to examine the behavior of autocorrelation function and partial autocorrelation function to lag lengths on the figure. In general, the fit of the series to the AR model is determined by the partial autocorrelation function, and the fit to the MA model is determined by the autocorrelation function [18].

After the provisional model is determined, the significance of the parameters and the significance of the model are tested. After determining the tentative temporary model suitable for $\mathrm{p}, \mathrm{d}, \mathrm{q}$ degrees, the best (ie unbiased, consistent and efficient) estimates of the model parameters should be calculated. The estimation process is usually made with the help of package programs and the estimation with the smallest total square of error is selected. The hypotheses and test statistics for the significance of the model are as follows

$\mathrm{H}_{0}$ : Temporary Model Suitable.

$\mathrm{H}_{1}$ : Temporary Model Not Available.

$\sum \frac{\rho_{k}^{2}}{n-k} \sim \chi_{(k-p-q)}^{2}$

$\mathrm{k}$ : number of delays, $\mathrm{p}$ and $\mathrm{q}$ are the degrees of the non-seasonal ARIMA model [16], [17], [18].

Forecasting: at this stage, the forecasting is made assuming that the parameters of the model are determined correctly. Since ARIMA models do not require additional information for forecasting and the success of forecasting is high, especially in short-term forecasts, forecasting of the systematic part of time series is also widely used. While making predictions with the ARIMA model, first the expected value of the time series process is calculated, and then the future values are obtained by using the expected value [8], [16].

\section{III.PROBLEM SOLUTION}

At this stage, the forecasting performances for ARIMA models and WNN are compared. The root mean square error (RMSE) was used as the performance criterion. For the data set, the number of Covid-19 cases and deaths between 11.12.202011.04.2021 were discussed. The performance of the models was examined not only for one country but also for three different countries. These countries are Turkey, Italy, and the United Kingdom [19], [20].

First, Turkey data were discussed for new cases. ARIMA models' results are given in Table 1.

Table 1: ARIMA Model Results for COVID-19 New Cases Time Series (Turkey)

\begin{tabular}{|c|c|c|}
\hline Model & Parameters & RMSE \\
\hline ARIMA (1,1,0) & AR (1) & 1556,61 \\
\hline ARIMA (1,1,1) & AR (1) & \\
& MA (1) & 1535,39 \\
\hline ARIMA (2,1,0) & AR (1) & \\
& AR (2) & 1538,64 \\
\hline ARIMA (2,1,1) & AR (1) & \\
& AR (2) & \\
& MA (1) & 1552,85 \\
\hline
\end{tabular}

The best model in ARIMA models is ARIMA $(1,1,1)$ according to RMSE values.

Mexican hat wavelet function and sigmoid function are used as hidden layer and output layer activation functions of WNN respectively, both new cases and deaths. The data set is divided into $70 \%$ training and $30 \%$ testing. The trained network is tested using the test dataset. With a constant learning rate $(0.01)$, the optimum number of hidden nodes was set to 40 and the iteration was set to 1000 . WNN results given in Table 2.

Table 2: WNN Model Results for COVID-19 New Cases Time Series (Turkey)

\begin{tabular}{|c|c|}
\hline Model & RMSE \\
\hline WNN & 4041,56 \\
\hline
\end{tabular}


Turkey data were discussed for deaths. ARIMA models' results are given in Table 3 .

Table 3: ARIMA Model Results for COVID-19 deaths Time Series (Turkey)

\begin{tabular}{|c|c|c|}
\hline Model & Parameters & RMSE \\
\hline ARIMA (1,1,0) & AR (1) & 8,65 \\
\hline ARIMA (1,1,1) & AR (1) & \\
& MA (1) & 8,55 \\
\hline ARIMA (2,1,0) & AR (1) & \\
& AR (2) & 8,58 \\
\hline ARIMA (2,1,1) & AR (1) & \\
& AR (2) & \\
& MA (1) & 8,62 \\
\hline
\end{tabular}

The best model in ARIMA models is ARIMA $(1,1,1)$ according to RMSE values.

WNN results given in Table 4.

Table 4: WNN Model Results for COVID-19 Deaths Time Series (Turkey)

\begin{tabular}{|c|c|}
\hline Model & RMSE \\
\hline WNN & 19,88 \\
\hline
\end{tabular}

Secondly, Italy data were discussed for new cases. ARIMA models' results are given in Table 5.

Table 5: ARIMA Model Results for COVID-19 New Cases Time Series (Italy)

\begin{tabular}{|c|c|c|}
\hline Model & Parameters & RMSE \\
\hline ARIMA (1,1,0) & AR (1) & 3333,603 \\
\hline ARIMA (1,1,1) & AR (1) & \\
& MA (1) & 3235,294 \\
\hline ARIMA (2,1,0) & AR (1) & \\
& AR (2) & 3206,696 \\
\hline ARIMA (2,1,1) & AR (1) & \\
& AR (2) & \\
& MA (1) & 3210,791 \\
\hline
\end{tabular}

The best model in ARIMA models is ARIMA $(2,1,0)$ according to RMSE values.

WNN results given in Table 6 .

Table 6: WNN Model Results for COVID-19 New Cases Time Series (Italy)

\begin{tabular}{|c|c|}
\hline Model & RMSE \\
\hline WNN & 1806,52 \\
\hline
\end{tabular}

Italy data were discussed for deaths. ARIMA models' results are given in Table 7.
Table 7: ARIMA Model Results for COVID-19 Deaths Time Series (Italy)

\begin{tabular}{|c|c|c|}
\hline Model & Parameters & RMSE \\
\hline ARIMA (1,1,0) & AR (1) & 109,09 \\
\hline ARIMA (1,1,1) & AR (1) & \\
& MA (1) & 96,57 \\
\hline ARIMA (2,1,0) & AR (1) & \\
& AR (2) & 105,09 \\
\hline ARIMA (2,1,1) & AR (1) & \\
& AR (2) & \\
& MA (1) & 94,05 \\
\hline
\end{tabular}

The best model in ARIMA models is ARIMA $(2,1,1)$ according to RMSE values.

WNN results given in Table 8 .

Table 8: WNN Model Results for COVID-19

\begin{tabular}{|c|c|} 
Deaths Time Series (Turkey) \\
\hline Model & RMSE \\
\hline WNN & 78,49 \\
\hline
\end{tabular}

Finally, United Kingdom data were discussed for new cases. ARIMA models' results are given in Table 9.

Table 9: ARIMA Model Results for COVID-19 New Cases Time Series (United Kingdom)

\begin{tabular}{|c|c|c|}
\hline Model & Parameters & RMSE \\
\hline ARIMA (1,1,0) & AR (1) & 3943,263 \\
\hline ARIMA (1,1,1) & AR (1) & \\
& MA (1) & 3958,173 \\
\hline ARIMA (2,1,0) & AR (1) & \\
& AR (2) & 3959,685 \\
\hline ARIMA (2,1,1) & AR (1) & \\
& AR (2) & \\
& MA (1) & 3975,505 \\
\hline
\end{tabular}

The best model in ARIMA models is ARIMA $(1,1,0)$ according to RMSE values.

WNN results given in Table 10.

Table 10: WNN Model Results for COVID-19 New Cases Time Series (United Kingdom)

\begin{tabular}{|c|c|}
\hline Model & RMSE \\
\hline WNN & 1010,79 \\
\hline
\end{tabular}

United Kingdom data were discussed for deaths. ARIMA models' results are given in Table 11.

Table 11: ARIMA Model Results for COVID-19

Deaths Time Series (United Kingdom)

\begin{tabular}{|c|c|c|}
\hline Model & Parameters & RMSE \\
\hline ARIMA $(1,1,0)$ & AR (1) & 284,15 \\
\hline
\end{tabular}




\begin{tabular}{|l|l|l|}
\hline ARIMA (1,1,1) & AR (1) & \\
& MA (1) & 259,03 \\
\hline ARIMA (2,1,0) & AR (1) & \\
& AR (2) & 230,79 \\
\hline ARIMA (2,1,1) & AR (1) & \\
& AR (2) & \\
& MA (1) & 227,64 \\
\hline
\end{tabular}

The best model in ARIMA models is ARIMA $(2,1,1)$ according to RMSE values.

WNN results given in Table 12.

Table 12: WNN Model Results for COVID-19

Deaths Time Series (United Kingdom)

\begin{tabular}{|c|c|}
\hline Model & RMSE \\
\hline WNN & 16,84 \\
\hline
\end{tabular}

\section{CONCLUSION}

In this study, autoregressive integrated moving average (ARIMA) time series model and Wavelet Neural Networks (WNN) methods have been applied to predict new COVID-19 cases and new deaths in Turkey, Italy, and the United Kingdom. For the data set, the number of Covid-19 cases and deaths between 11.12.2020-11.04.2021 were discussed. Based on this period, we wished to forecast new cases and new death of the future 10 days. We have used RMSE as the performance indicators for the studied models. Our application demonstrated WNN has performed extremely well in terms of forecasting consistency both new case and new death except Turkey data. The reason for this is thought to be due to the change in the way Turkey data is collected. Moreover, we suppose that the concept of WNN architecture has been implemented for the first time in this study, which showed robust forecasting performance for the studied countries. In conclusion, WNN models that can be performed efficiently at any time for any country for short-term forecasting of this pandemic, which should not be ignored.

\section{REFERENCES}

[1] Ozdemir, O. and Kaya, A., Geleceğin Dünyasında Bilimsel ve Mesleki Çallşmalar 2019-Matematik ve Fen Bilimleri, Dalgacık Sinir A $\breve{g} l$ Mimarisinde Aktivasyon
Fonksiyonlarının Karşılaştırılması, Ekin Basım Yayın Dağıtım, 2019.

[2] Jordan M.I., Why the logistic function? A tutorial discussion on probabilities and neural networks, Computational Cognitive Science Technical Report 9503, Massachusetts Institute of Technology, 1995.

[3] Liu, Y. and Yao, X., Evolutionary Design of Artificial Neural Networks with Different Nodes, In Proceedings of the Third IEEE International Conference on Evolutionary Computation, 1996, pp. 570-675.

[4] Sopena J.M., Romero E., Alqu'ezar, R., Neural networks with periodic and monotonic activation functions: a comparative study in classification problems, In Proceedings of the 9th International Conference on Artificial Neural Networks, 1999, pp. 323-328.

[5] Dorffner G., Unified frameworks for MLP and RBFNs: Introducing Conic Section Function Networks, Cybernetics and Systems, Vol. 25, 1994, pp. 511-554.

[6] Bodyanskiy Y., Lamonova N. and Vynokurova, O., Double-Wavelet Neuron Based on Analytical Activation Functions, International Journal Information Theories \& Applications, Vol. 14, 2007, pp. 281-288.

[7] Özmen, A., Mevsimsel Dalgalanmalar İçermeyen Zaman Serilerinde Kısa Dönem Öngörü Amaçlı Box-Jenkins (ARIMA) Modellerinin Kullanımı, Fen-Edebiyat Fakültesi Dergisi, Vol. 2, No. 1, 1989, pp.105120.

[8] Kutlar, A., Uygulamalı Ekonometri, Nobel Yayınları, 2005.

[9] Gujarat1, D., Temel Ekonometri, 1999.

[10] Grossmann A. and Morlet, J., Decomposition of Hardy functions into square integrable wavelets of constant shape, SIAM Journal on Mathematical Analysis, Vol. 15, No. 4, 1984, pp. 723-736.

[11] Zhang, Q. and Benveniste, A., Wavelet networks, CTrans. Neural Networks, 1992, pp. 889-898.

[12] Said, S., Jemai, O., Zaied, M. and Ben Amar, C., 3D fast wavelet network model-assisted 3D face recognition, Eighth International Conference on Machine Vision, 2015.

[13] Said, S., Jemai, O., Zaied, M. and Ben Amar, C., Wavelet networks for facial emotion recognition, 15th International Conference on Intelligent Systems Design and Applications, 2015, pp. 295-300.

[14] Bouchrika, T., Zaied, M., Jemai, O. and Ben Amar, C., Neural solutions to interact with 
computers by hand gesture recognition, Multimedia Tools and Applications, 2014, pp. 2949-2975.

[15] Ejbali, R., Jemai, O., Zaied, M. and Ben Amar, C., A speech recognition system using fast learning algorithm and beta wavelet network, 15th International Conference on Intelligent Systems Design and Applications, 2015, pp. 1418.

[16] Akgül, I., Zaman Serilerinin Analizi ve ARIMA Modelleri, Der Yayınları, 2003.

[17] Kadılar, C., SPSS Uygulamalı Zaman Serileri Analizine Giriş, Bizim Büro Basımevi, 2005.

[18] Sevüktekin, M. and Nargeleçekenler, M., Zaman Serileri Analizi, Nobel Yayınları, 2005.

[19] https://ourworldindata.org/coronavirus.

[20] https://covid19.saglik.gov.tr/TR-66935/genelkoronavirus-tablosu.html.

\section{Creative Commons Attribution}

\section{License 4.0 (Attribution 4.0}

\section{International , CC BY 4.0)}

This article is published under the terms of the Creative Commons Attribution License 4.0

https://creativecommons.org/licenses/by/4.0/deed.en $\underline{\underline{U S}}$ 